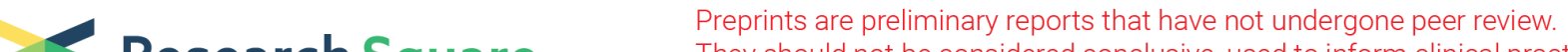 $\begin{array}{ll}\text { Research Square } & \begin{array}{l}\text { They should not be considered conclusive, used to inform clinical practice, } \\ \text { or referenced by the media as validated information. }\end{array}\end{array}$
}

\section{Stab Wound with a Missed Broken Blade near Thoracic Vertebrae}

\section{Amin sadeghNejad}

Islamic Azad University Tehran Medical Sciences

\section{Ehsan Seif}

Alborz University of Medical Sciences

shaghayegh mousavi

Alborz University of Medical Sciences

mojtaba ahmadinejad ( $\sim$ Abzums.ac@gmail.com )

Alborz University of Medical Sciences https://orcid.org/0000-0001-6777-2046

\section{Research Article}

Keywords: stab wound, foreign body, spinal cord, surgical treatment-trauma

Posted Date: September 13th, 2021

DOI: https://doi.org/10.21203/rs.3.rs-352806/v1

License: (c) (1) This work is licensed under a Creative Commons Attribution 4.0 International License. Read Full License 


\section{Abstract}

The authors report a case of a 19-year-old man who was stabbed in the thoracic area and the blade of knife was broken deep inside near the spine. The blade was surgically removed without any serious damage to the spinal cord, main vessels, and organs and the patient had no problems after surgery.

\section{Introduction}

Stab wounds to the spinal cord are relatively infrequent [1]. In a stab wound of the lower cervical and upper dorsal region, the thoracic cage is penetrated. When this occurs, the lung, the heart, the pericardium, any of the vessels in the thoracic cage, the esophagus or trachea, or even the thoracic duct may be cut [2]. In this article, we report the case of a 19-year-old man who was attacked with a knife, and a broken blade of it had remained next to his thoracic spine. The foreign body did not damage vital organs and was surgically removed.

\section{Case Presentation}

This report is about a 19-year-old young man who complained of upper back pain in the area between the medial border of the left scapula and the spine and came to our hospital emergency room. The patient states that he was stabbed in that area 3 days ago during a fight. He was then referred to a local clinic and the wound was disinfected and bandaged on an outpatient basis. After 3 days, the wound becomes swollen and painful and the patient was referred to a general hospital. In the emergency room, the patient's vital signs were stable. Examination showed a swelled and erythematous wound $(7.5 \mathrm{~cm}$ long) between the left scapula and T2 vertebrae, over the third rib on his back. There was no discharge or hemorrhage from the wound. The patient had no complaints other than a pain in the wound area. The patient did not have a fever and shortness of breath. There were no positive findings on neuromuscular examination. Also, the Complete blood count (CBC) is in the normal range. (Hemoglobin: $13.4 \mathrm{gr} / \mathrm{dl}$, White blood cells: $7600 / \mathrm{mm} 3$ ). In the chest X-ray obtained from the patient, a foreign object was accidentally found near the vertebral column at T2/T3 level with "metallic density" (Fig. 1A). Therefore a CT scan without contrast was performed for a more accurate evaluation. In CT scan a sharp object was found at $\mathrm{t} 2$ / $\mathrm{t} 3$ level beside the vertebral column, which is thought to be broken blade of the knife (Fig. 1B). The patient was admitted to surgical service to remove the foreign body. A full detailed Examination of the nervous system was performed to investigate possible spinal cord injury. The patient did not have any neurological defects. Due to the presence of important elements at the wound site such as the aortic arch, left subclavian artery and vein, left common carotid artery and left internal jugular vein, a CT angiography was performed for the patient that showed No damage to the main vessels or hemorrhage (although the tip of foreign object is few millimeters apart from left common carotid artery) (Fig. 2). After 3 days of admission to the hospital and antibiotic therapy (intravenous cefazolin 4 times a day), the patient went to the operating room to remove the foreign body. The patient went under general anesthesia and in the prone position, wound site first opened, and a sharp metal object was removed. (Fig. 3, broken tip of the knife), the damaged part of the superior lobe of the left lung was rebuilt and 
muscles were sutured. Then a chest tube was placed at the left mid-clavicle line in the second intercostal space the surgery took about one and a half hours and the patient was transferred to the ward after one day in the recovery room without any problem. The patient had no post-operative complaints other than pain at the operation site. The neurological examinations had not any positive findings. One day after the operation, a chest X-ray was taken for the patient, which was reported to be normal, and the patient's chest tube was removed after two days and the patient was discharged.

\section{Discussion}

The importance of this case report is that a full examination and exploration of wound site in stab wound cases is very important and vital. Accurate imaging studies were necessary to locate the foreign body and assess spinal cord damage. Standard plain x-ray graphy and CT scan were essential for delineating the bony anatomy and fracture, simultaneously localizing the trajectory of the foreign bodies and fragments within the spinal canal [3]. In this case, the knife blade was broken and remained deep in the wound and impacted by the muscles. Therefore, the initial examination with a simple chest $\mathrm{x}$-ray could show the existence of a foreign body especially in such cases that the foreign body is deep in tissue and not observed by wound exploration. As if in the early exploration of the wound, its presence was not known. In this case, the foreign body was remained in place by impaction with surrounding muscles such as the trapezius and rhomboid and also the absence of an outer part on the body surface, are reasons that it didn't cause serious damage to important adjacent elements such as spinal cord or major veins, despite its sharp nature. Surgical extraction of foreign body may prevent further infection, myelopathy, and delayed neurological loss and It is recommended that sharp fragments (e.g., a knife tip) be removed irrespective of spinal level to prevent worsening.[4][5]. So in this case we surgically removed foreign body for patient.

\section{Declarations}

Funding: This research received no specific grant from any funding agency in the public, commercial, or not for-profit sectors.

Conflict of interest: On behalf of all authors, the corresponding author states that there is no conflict of interest.

Ethical approval: Alborz University of medical Sciences does not require ethical approval for reporting individual cases or case series.

Informed Consent: Written informed consent was obtained from the patient(s) for their anonymized information to be published in this article.

Availability of data and material: available

Code availability: available 
Contributor ship: Shaghayegh Mousavi and Mojtaba Ahmadinejad researched literature and conceived the study. Amin Sadeghnejad wrote the first draft of the manuscript. Ehsan Seif reviewed and edited the manuscript and all authors approved the final version of the manuscript.

\section{References}

1. Jones FD, Woosley RE. Delayed myelopathy secondary to retained intraspinal metallic fragment: Case report. Journal of neurosurgery. 1981 Dec 1;55(6):979-82.

2. Lipschitz R. Associated injuries and complications of stab wounds of the spinal cord. Spinal Cord. 1967 Aug;5(2):75-82.

3. Jallo GI . Neurosurgical management of penetrating spinal injury . Surg Neurol 1997; $47: 328-30$.

4. Williams DT, Chang DL, DeClerck MP. Penetrating spinal cord injuries with retained canal fragments. Canadian Journal of Emergency Medicine. 2009 Mar;11(2):172-3.

5. Manzone P, Domenech V, Forlino D. Stab injury of the spinal cord surgically treated. Clinical Spine Surgery. 2001 Jun 1;14(3):264-7.

\section{Figures}




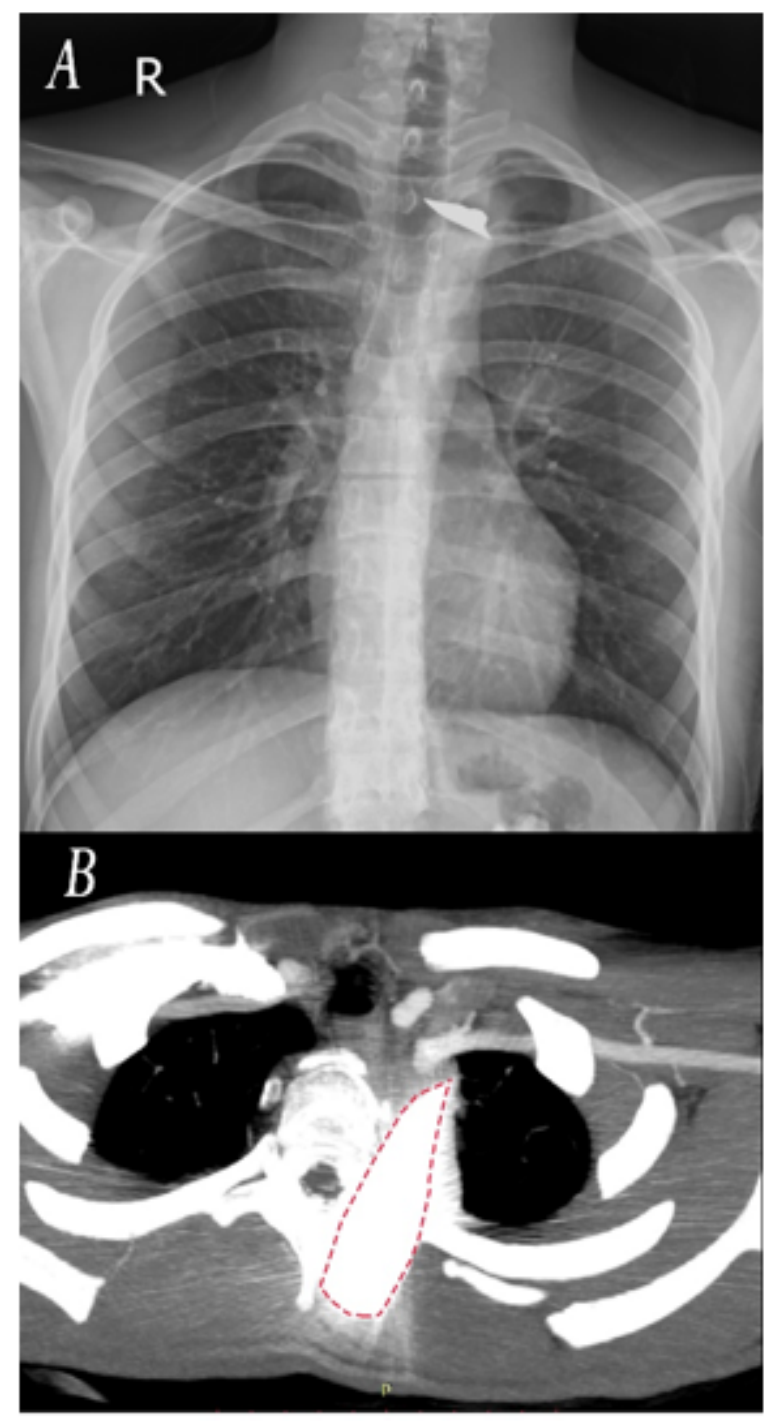

figure 1.(A) foreign body shown in chest $x$-ray . (B) computed tomographic image(CT Scan) indicates the location of broken knife blade.

\section{Figure 1}

See image above for figure legend 


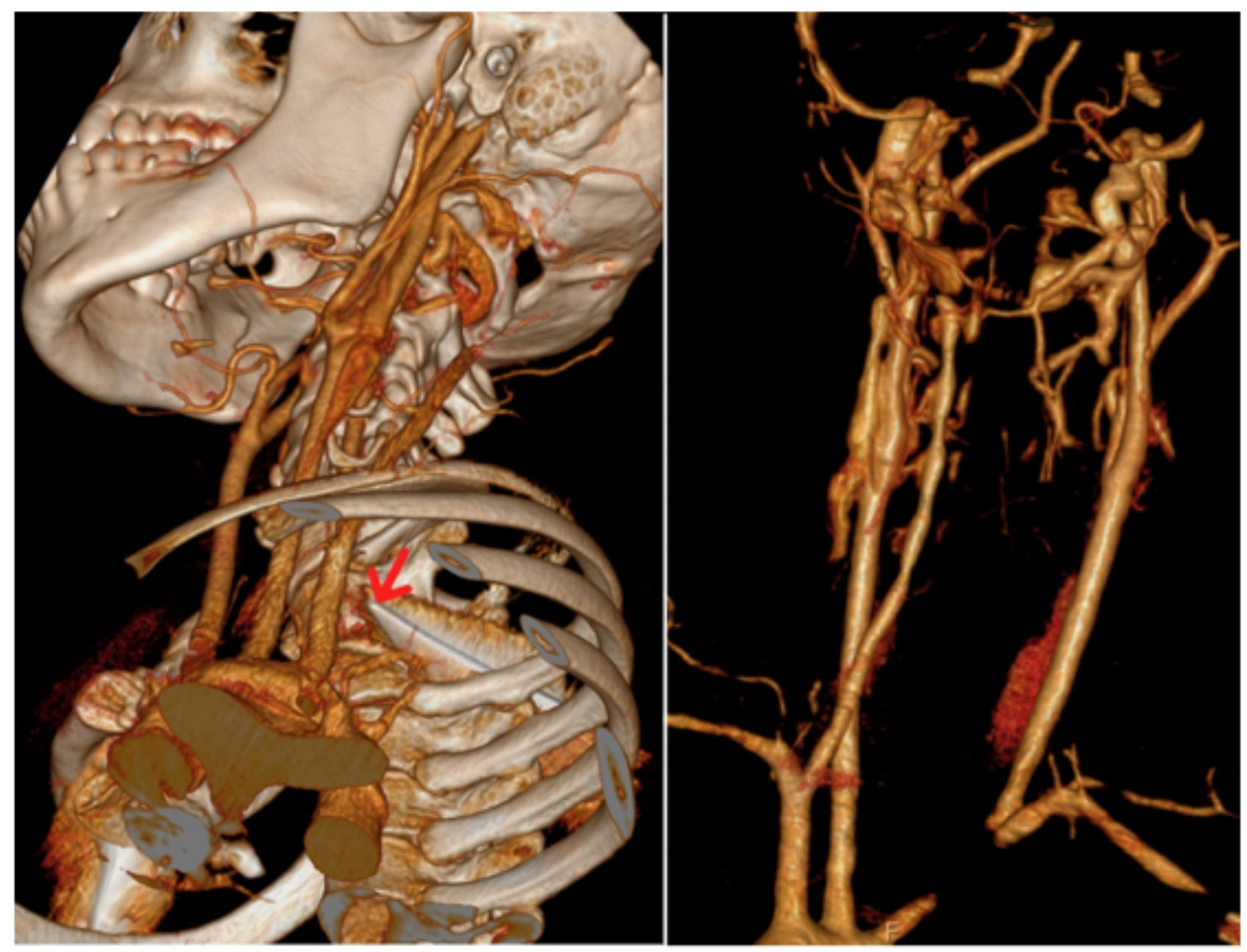

figure 2:computed tomographic angiography showed no injury to vessels. the tip of broken blade is indicated with red arrow.

Figure 2

See image above for figure legend 


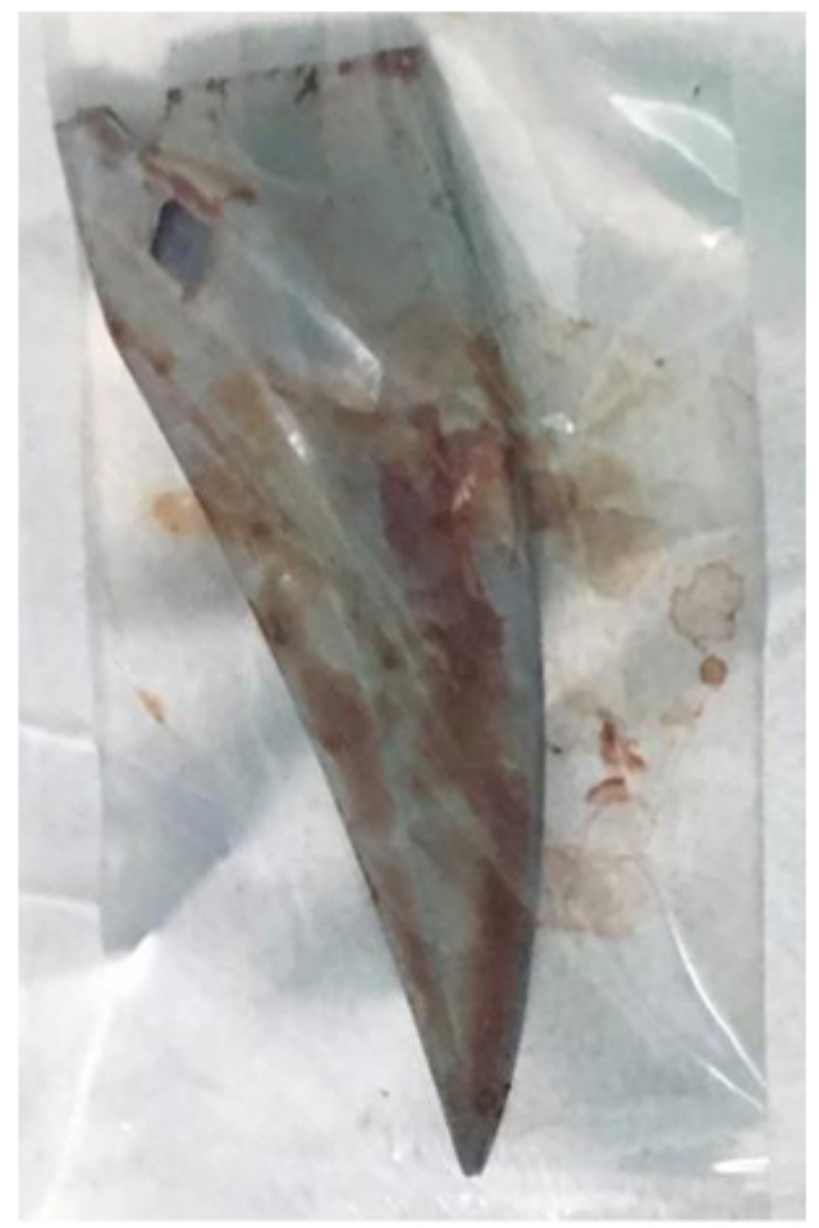

figure 3.Removed foreign body

Figure 3

See image above for figure legend 